\title{
A rare complication of laparoscopic low anterior resection: Colonic necrosis and prolapsus of it
}

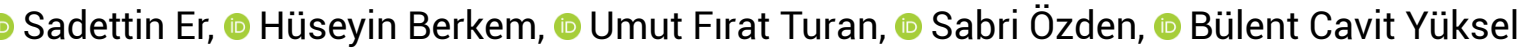 \\ Department of General Surgery, Colorectal Clinic, Health Sciences University Ankara Numune Training and Research Hospital, Ankara, Turkey
}

To the Editor,

Colorectal cancer (CRC) is one of the most common malignancies and the leading causes of cancer-related death world wide. ${ }^{[1]}$ Surgery is the corner stone of curative treatment for patients with resectable CRC. ${ }^{[2]}$ Laparoscopic-assisted surgery has been widely accepted as an alternative to conventional open surgery for CRC. ${ }^{[3]}$

Colonoscopy was performed on a 57-year-old male patient with the complaint of stomachache and revealed a $10-\mathrm{cm}$ mass beginning from the rectum. The biopsy results were indicative of adenocarcinoma. For surgical staging, thoracoabdominal computed tomography was undertaken. Since metastasis was not determined in this examination, the laparoscopic low anterior resection (LAR) procedure was applied. The patient was discharged within post-operative 10 days without any problem. However, eight days after the discharge, the patient was readmitted to the hospital due to anal drip and prolapse. There were no peritoneal irritation findings. The rectal examination revealed necrosis and prolapse of the colon segment (Fig. 1a and b). Laparotomy was performed and complete necrosis was observed covering a $12 \mathrm{~cm}$ area of the descending colon, and luminal continuity was provided by the surrounding organs and structures. The Hartmann procedure was performed on the patient and he was discharged on postoperative day 15.
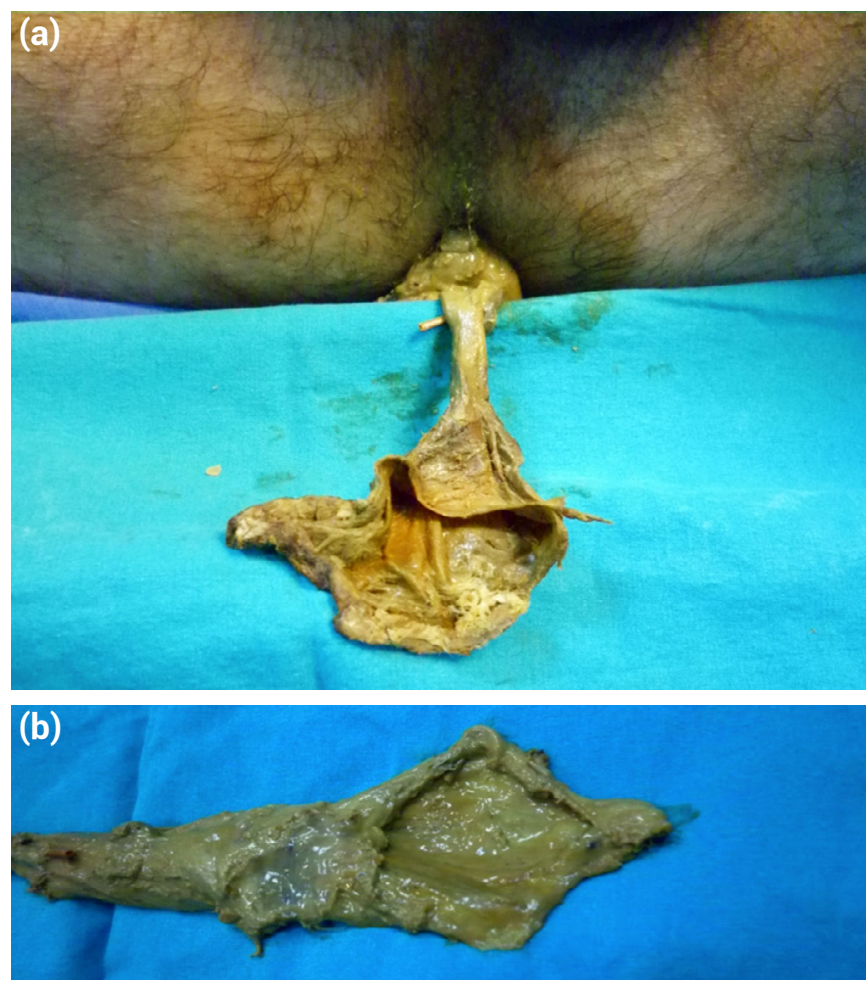

Figure 1. (a) Necrotic and prolapsed colon segment. (b) Necrotic colon segment.

Many complications may develop after laparoscopic LAR, such as intestinal obstruction, ischemic colitis, perianal abscess, wound infection, anastomotic leakage, anastomotic stricture, rectovaginal fistulas, rectovesical fistula, fecal incontinence, pneumonia, and strangulation of the 
intestine ${ }^{[4]}$ However, to date, colonic necrosis and prolapse has not been reported in the literature as a complication after laparoscopic rectal surgery. We presented this rare case to attract surgeons' attention to the possibility of this complication after LAR.

\section{Disclosures}

Peer-review: Externally peer-reviewed.

Conflict of Interest: None declared.

\section{References}

1. Siegel RL, Miller KD, Jemal A. Cancer statistics, 2016. CA
Cancer J Clin 2016;66:7-30. [CrossRef]

2. Morneau M, Boulanger J, Charlebois P, Latulippe JF, Lougnarath $\mathrm{R}$, Thibault $\mathrm{C}$, et al. Laparoscopic versus open surgery for the treatment of colorectal cancer: a literature review and recommendations from the Comité de l'évolution des pratiques en oncologie. Can J Surg 2013;56:297-310. [CrossRef]

3. Jin K, Wang J, Lan H, Zhang R. Laparoscopic surgery for colorectal cancer in China: an overview. Int $\mathrm{J}$ Clin Exp Med 2014;7:4635-45.

4. Park EJ, Baik SH, Kang J, Hur H, Min BS, Lee KY, et al. The Impact of Postoperative Complications on Long-term Oncologic Outcomes After Laparoscopic Low Anterior Resection for Rectal Cancer. Medicine (Baltimore) 2016;95:e3271. 